\title{
Preparation of Poly Aniline by Chemical Oxidative Method and Its Characterization
}

\author{
Tassew Alemayehu, Diribe Abiebie \\ College of Natural and Computational Sciences, Department of Chemistry, Adigrat University, Adigrat, Ethiopia \\ Email: tass.alex21@gmail.com
}

Received 10 July 2014; revised 15 August 2014; accepted 20 September 2014

Copyright (C) 2014 by authors and OALib.

This work is licensed under the Creative Commons Attribution International License (CC BY).

http://creativecommons.org/licenses/by/4.0/

(c) (i)

\begin{abstract}
The present work reports the oxidative synthesis of poly aniline using $\mathrm{K}_{2} \mathrm{Cr}_{2} \mathrm{O}_{7}$ as an oxidizing agent and $\mathrm{H}_{2} \mathrm{SO}_{4}$ as dopant. The synthesized polymer was characterized by solubility test and UVvisible spectroscopic technique. The synthesized polymer (poly aniline) was insoluble in ethanol, acetone, benzene and water. The absorbance of UV-visible spectra shows two reductive peaks at some wake length. The band observed at 327 - 365 nm for the PANI samples corresponds to n-p ${ }^{*}$ transitions of aniline and the broad band at $600-620 \mathrm{~nm}$ is due to $n-p^{*}$ transitions of quinine-imine groups.
\end{abstract}

Keywords

Doping, Poly Aniline, UV-Visible Spectra, Solubility Test

Subject Areas: High Polymer Chemistry, Organic Polymer Materials

\section{Introduction}

Polymers are high molecular weights which built up a large number of small molecules called monomers (low molecular weight substance which when redacted under suitable conditions links together to produce high molecular weight polymer). Some of two or three different units repeat a number of times in a polymer. In the laboratory the preparation of polymers involves looking together of many small molecules [1].

Polymers can be classified in several different ways according to their structures, physical properties or types of reaction by which they undergo. However, these classifications are not independent of each others. On the basis of their structure, we can split polymers into two main types. These are homo polymer and copolymers. In homo polymers there is only one monomer unit present. But in copolymer we have two or more different monomer units [2].

Aniline is an organic base used to make dyes, drugs, explosive, plastics and photographic and rubber chemical and was first obtained in 1826 by the destructive distillation of indigo. Its name is taken from the specific name

How to cite this paper: Alemayehu, T. and Abiebie, D. (2014) Preparation of Poly Aniline by Chemical Oxidative Method and Its Characterization. Open Access Library Journal, 1: e974. http://dx.doi.org/10.4236/oalib.1100974 
of the indigo-yielding plant indigo era anile with chemical formula of $\mathrm{C}_{6} \mathrm{H}_{5} \mathrm{NH}_{2}$. Aniline is prepared commercially by catalytical hydrogenation of nitro benzene or by the action of ammonia on chlorobenzene. In an acidic medium, nitrous acid converts aniline into adiazonium salt that is an intermediate in the preparation of a great number of dyes and other organic compounds. Pure aniline is a highly poisonous and colorless substance with a pleasant odor [3] [4].

Poly aniline was first know in 1835 as "Aniline black", a term used for product obtained by the oxidation of aniline, the interest in poly aniline as an important conducting polymer has increased significantly over the past decade. The poly anilines refer to a large class of conducting polymers which have the following general formula represented in Figure 1 below [5].

\subsection{Objective}

\subsubsection{General Objective}

The main objective of this study relies on the preparation of poly aniline by chemical oxidative method and characterizing it.

\subsubsection{Specific Objective}

To attain this main objective the following specific were include like familiarizing with preparation methods of poly aniline, studying the solubility of poly aniline and familiarizing with the poly aniline characterization methods.

\section{Methodology}

\subsection{Equipments and Chemicals}

Equipments employed or used in this work include suction filtration, UV-visible spectrometry, filter paper, dropper, beaker, volumetric flask, round bottom flask, stirrer, electronic balance, mortar, pestil grinder, electronic centrifugation, and measuring cylinder.

\section{Chemicals}

The chemicals used in this work were also $\mathrm{H}_{2} \mathrm{SO}_{4}, \mathrm{~K}_{2} \mathrm{Cr}_{2} \mathrm{O}_{7}$, aniline, ethanol, acetone, benzene, and distilled water.

\subsection{Solution Preparation}

1) $0.04 \mathrm{M}$ of $\mathrm{K}_{2} \mathrm{Cr}_{2} \mathrm{O}_{7}$ was prepared by dissolving $2.94 \mathrm{~g}$ of $\mathrm{K}_{2} \mathrm{Cr}_{2} \mathrm{O}_{7}$ in $250 \mathrm{ml}$ volumetric flask with distilled water.

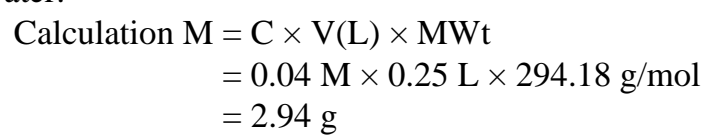

2) $0.1 \mathrm{M}$ of $\mathrm{H}_{2} \mathrm{SO}_{4}$ was prepared by diluting $1.39 \mathrm{ml} \mathrm{H}_{2} \mathrm{SO}_{4}$ in $250 \mathrm{ml}$ volumetric flask with distilled water.

For solution preparation from liquids its formula is as follow.

$\mathrm{C}_{1} \mathrm{~V}_{1}=\mathrm{C}_{2} \mathrm{~V}_{2}$ from dilution law. $\mathrm{V}_{1}=\mathrm{C}_{2} \mathrm{~V}_{2}=0.1 \mathrm{M} \times 0.25 \mathrm{l}=1.39 \mathrm{ml}$

$$
\mathrm{C}_{1} \quad 18 \mathrm{~m}
$$

3) $0.1 \mathrm{M}$ of aniline (l) was prepared by diluted $2.34 \mathrm{ml}$ of aniline in $250 \mathrm{ml}$ of volumetric flask with distilled water.

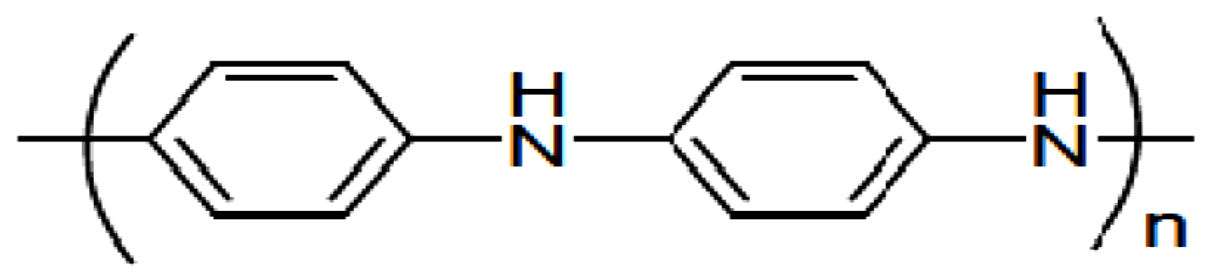

Figure 1. General formula of poly aniline [6]. 


$$
\begin{array}{ll}
\mathrm{C}_{1} \mathrm{~V}_{1}=\mathrm{C}_{2} \mathrm{~V}_{2} \mathrm{~V}_{1}= & \mathrm{C}_{2} \mathrm{~V}_{2}=0.1 \mathrm{~m} \times 0.25 \mathrm{~L}=2.34 \mathrm{ml} \\
\mathrm{C}_{1} & 10.7 \mathrm{~m}
\end{array}
$$

\subsection{Experimental Procedures}

In this experiment to prepare poly aniline $50 \mathrm{ml}$ of $0.1 \mathrm{M}$ of aniline was taken into $250 \mathrm{ml}$ volumetric flask and $50 \mathrm{ml}$ of $0.1 \mathrm{~m} \mathrm{H}_{2} \mathrm{SO}_{4}$ was added. Again at appropriate oxidant $20 \mathrm{ml}$ of $0.04 \mathrm{~m} \mathrm{~K}_{2} \mathrm{Cr}_{2} \mathrm{O}_{7}$ aqueous solutions was slowly added to the reaction medium for about 20 minutes by using dropping funnel and the precipitate was formed. Then the precipitate formation on the polymerization reaction was filtered at the end of final product by using suction filtration. Again the final product was washed by using diluted solution of $\mathrm{H}_{2} \mathrm{SO}_{4}$ and dried at $60^{\circ} \mathrm{C}$ in vacuum for 12 hours. Then the synthesized product (poly aniline) was grinded by using grinder and the solubility of the powder was checked in different solvents like acetones, benzenes, ethanol and water was checked and absorbance value was recorded using UV-Vis spectrophotometer.

\section{Result and Discussion}

1) Solubility

The Solubility of sulfuric acid doped poly aniline was analyzed in various solvents. Sulfuric acid doped PANI was insoluble in solvents like acetone, benzene, methanol and water. According to some literatures PANIS is Soluble in DMSO but there was no DMSO at the laboratory to check the solubility [6].

2) Absorbance measurement

The UV-visible spectra of the PANI synthesized with the use of $\mathrm{K}_{2} \mathrm{Cr}_{2} \mathrm{O}_{7}$ in $\mathrm{H}_{2} \mathrm{SO}_{4}$ media was measured by dissolving $0.057 \mathrm{~g}$ of poly aniline green powder in $10 \mathrm{ml}$ of $\mathrm{H}_{2} \mathrm{O}$ that was placed in to electronic centrifugation at 600 revolving frequency for 10 minutes to measure its Absorbents different wave lengths. The absorbance of PANI was recorded as show in the following (Table 1 ).

Figure 2 shows the graph of wavelength versus absorbance of poly aniline. In the figure absorbance represented as Abs is plotted at the y-axis ranging from 0 to 1 and wavelength in nanometer $(\mathrm{nm})$ is plotted at the $\mathrm{X}$-axis ranging from $250 \mathrm{~nm}$ to $600 \mathrm{~nm}$. As can see in the figure poly aniline gives two reductive peaks occur at around $350 \mathrm{~nm}$ and $600 \mathrm{~nm}$ wave lengths. Aniline has a good ability of absorbance around 0.96 at $350 \mathrm{~nm}$ wave

\begin{tabular}{cc} 
Table 1. Absorbance of PANI at different wave lengths. \\
\hline$\lambda(\mathrm{nm})$ & Absorbance \\
$350 \mathrm{~nm}$ & 0.958 \\
$450 \mathrm{~nm}$ & 0.108 \\
$550 \mathrm{~nm}$ & -0.301 \\
$650 \mathrm{~nm}$ & 0.054 \\
$750 \mathrm{~nm}$ & -0.040 \\
\hline
\end{tabular}

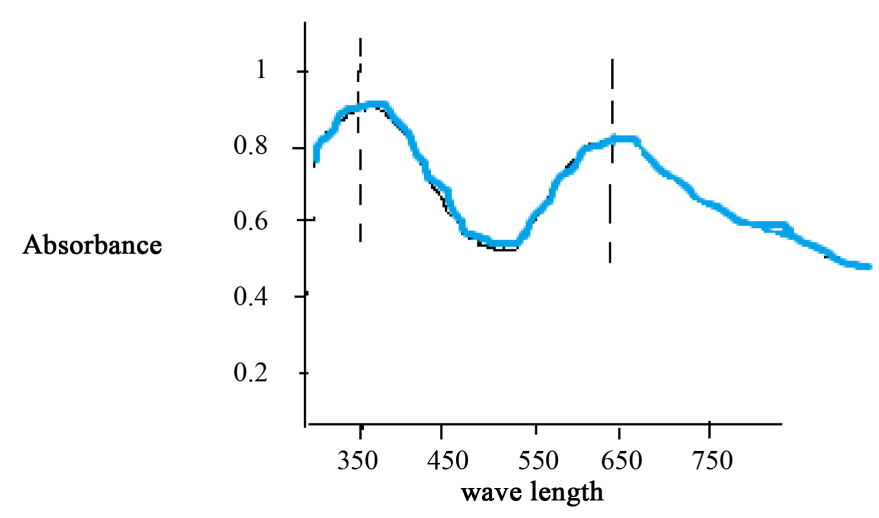

Figure 2. Plot of absorbance peak at y-axis for poly aniline at different wave lengths at $\mathrm{x}$-axis. 
length. The band observed at $350 \mathrm{~nm}$ for the PANI samples corresponds to $\mathrm{n}-\pi^{*}$ transitions of aniline. The broad band's at $600-620 \mathrm{~nm}$ is due to $\mathrm{n}-\pi^{*}$ transitions of amine groups [6].

The reaction that represents preparation of poly aniline is as follow.

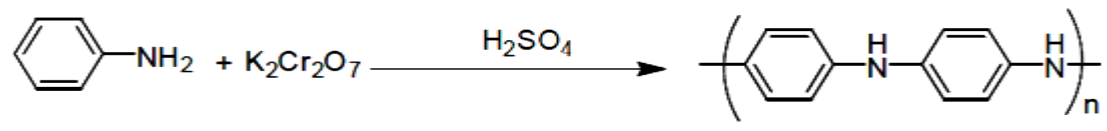

\section{Conclusion and Recommendation}

\subsection{Conclusion}

In this research the result shows that the synthesized $\mathrm{H}_{2} \mathrm{SO}_{4}$ doped poly aniline is in soluble in solvent like acetone, benzene, methanol, and water. Based on the closeness of UV-visible absorbance, results of this study with other related works indicated in review are possible to say that poly aniline can be synthesized by chemical polymerization method based on oxidative coupling in which this coupling involves oxidation of monomers to form a cation radical double by coupling called a dication.

\subsection{Recommendation}

Based on this study it is recommended that it is advisable to prepare polymers like poly aniline by chemical oxidative method even in the absence of well organized laboratory.

\section{References}

[1] Nunziante, P. and Pistoia, G. (1989) Conducting Polymers. ElectroChem, 34, 223.

[2] Maria, C. (2008) Organic Chemistry of Polyanilines. The Open Macromolecules Journal, 1, 58-73

[3] Cheruku, D. (2008) Electronic Devices and Circuits. 2nd Edition.

[4] Odian, G. (2004) Principles of Polymerization. 4th Edition, Wiley-Interscience, New York.

[5] Trivedi, D.C. (1997) Polyanilines. In: Nalwa, H.S., Ed., Handbook of Organic Conductive Molecules and Polymers, Conductive Polymers: Synthesis and Electrical Properties, Vol. 2, John Wiley \& Sons, New York.

[6] Vivekanandan, J., et al. (2011) Synthesis, Characterization and Conductivity Study of Poly Aniline Prepared by Chemical Oxidative and Electrochemical Methods. Archives of Applied Science Research, 3, 5. 